\title{
Coloboma of optic disc
}

INSERM

\section{Source}

INSERM. (1999). Orphanet: an online rare disease and orphan drug data base. Coloboma of optic disc. ORPHA:98947

Coloboma of optic disc is a rare, genetic, developmental defect of the eye characterized by a unilateral or bilateral, sharply demarcated, bowl-shaped, glistening white excavation on the optic disc (typically decentered inferiorly) which usually manifests with varying deg rees of reduced visual acuity. It can occur isolated or may associate other ocular (e.g. retinal detachment, retinoschisis-like separation) or systemic anomalies (e.g. renal). 